\section{Review: antidepressants associated with increased risk of suicidality in adults aged less than 25 years}

\section{QUESTION}

Question: What is the risk of suicidal behaviour within clinical trials of antidepressants in adults?

Outcomes: Primary outcome: definitive suicidal behaviour or ideation (completed suicide, attempted suicide or preparatory acts), secondary outcome: suicidal behaviour (preparatory actions).

\section{METHODS}

Design: Systematic review with meta-analysis.

Data sources: Data requested from 8 industry sponsors of 12 marketed antidepressant products were used. FDA-specified data formats provided instructions for identifying and classifying events possibly related to suicidality and how events would be classified. The search date was not reported, and the majority of trials were unpublished.

Study selection and analysis: Double-blind randomised placebo-controlled trials assessed the use of one of the 12 antidepressants in adults for any indication of suicidality. The antidepressants were bupropion, citalopram, duloxetine, escitalopram, fluoxetine, fluoxetine/olanzapine (ultimately excluded from the analysis), fluvoxamine, mirtazapine, nefazodone, paroxetine, sertraline and venlafaxine. A total of 372 trials $(\mathrm{n}=99231)$ were included in the dataset. Trials limited to known drug responders, those with fewer than 20 participants, studies not providing patient level data and studies with nonantidepressant active control were excluded. Individual patientlevel data were analysed using a conditional logistic regression model. Heterogeneity between studies was assessed.

\section{MAIN RESULTS}

There were a total of $8(0.01 \%)$ completed suicides, $134(0.14 \%)$ attempted suicides and $378(0.38 \%)$ people experiencing ideation alone. Overall, there was no increased risk of suicidality (ideation or worse) with active treatment versus placebo (OR 0.85, 95\% CI 0.71 to $1.02 ; \mathrm{p}=0.08$ ). Ideation or worse was rare in participants with non-psychiatric indications (12 out of 13284). Risk of ideation or worse was reduced in participants with any psychiatric indication, but this was of borderline significance (OR 0.83, 95\% CI 0.69 to 1.00; $p=0.05$ ). Suicide behavioural risk (completed suicide, attempted suicide or preparatory acts) was associated with age; participants aged $<25$ years had increased risk of suicidal behaviour with active treatment versus placebo, OR 2.30, 95\% CI 1.04 to 5.09. Treatment was associated with a reduced risk of suicidal behaviour in the age group of 25 to 64 years, but this was not significant (OR $0.87,95 \%$ CI 0.58 to 1.29). Participants aged $\geq 65$ years showed a reduced risk of suicidal behaviour with active drug treatment (OR $0.06,95 \%$ CI 0.01 to 0.58 ). When suicidal behaviour was grouped with ideation the age $<25$ years group showed a non-significant trend towards increased risk with active treatments (OR 1.62, 95\% CI 0.97 to 2.71), whereas both the 25 to 64 years age group and the group of persons aged $\geq 65$ years showed a reduced risk (OR $0.79,95 \%$ CI 0.64 to 0.98 ; OR $0.37,95 \% \mathrm{CI} 0.18$ to 0.76 respectively). When age was modelled as a continuous variable, the OR for suicidal behaviour or ideation declined at a rate of $2.6 \%$ per year of age $(-3.9 \%$ to $-1.3 \%$ $\mathrm{p}=0.0001$ ) and the OR for suicidal behaviour declined at a rate of $4.6 \%$ per year of age $(-7.4 \%$ to $-1.8 \% \mathrm{p}=0.001)$.

\section{CONCLUSIONS}

The evidence suggests that there is an increased risk of suicidal behaviour in adults aged $<25$ years who receive antidepressants. Those aged $\geq 25$ years have no increased or decreased risk (in people aged 65 years or older).

\section{ABSTRACTED FROM}

Stone M, Laughren T, Jones ML, et al. Risk f suicidality in clinical trials of antidepressants in adults: analysis of proprietary data submitted to US Food and Drug Administration. BMJ 2009;339:b2880.

Correspondence to: Marc Stone, Department of Drug Evaluation and Research, US Food and Drug Administration, 10903 New Hampshire Avenue, Silver Spring, MD 20993-0002, USA; marc.stone@fda.hhs.gov

Source of funding: This research received no specific grant from any funding agency in the public, commercial, or not-for-profit sectors.

- Additional notes are published online only at http://ebmh/bmj.com/content/vol13/ issue2 t has been known for a long time that antidepressants can increase the risk of suicidal thoughts and behaviour. ${ }^{1}$ Stone and colleagues have conducted a re-analyses of FDA data of 372 randomised placebo-controlled efficacy trials conducted not only in the indication of major depressive disorder but also in all other psychiatric and nonpsychiatric indications. Main results indicated that the risk for suicidal behaviour in patients aged $<25$ years taking antidepressants as compared to placebo was significantly elevated, neutral in patients aged 25 to 64 years and protective for those aged $\geq 65$ years. The second result was the strong agerelatedness of suicidal behaviour. On the basis of these two main results, the FDA ordered that for all antidepressants the existing black-box warning should be updated to include warnings about suicidality of young adults. However, such warnings may discourage psychiatrists from using antidepressants, which in turn might increase suicidality.
Gibbons $^{2}$ showed that after the release of the FDA warnings the antidepressant prescription rates decreased in the USA and the Netherlands, by about $22 \%$. Simultaneously, the suicide rates in youths increased up to $49 \%$ in the Netherlands and up to $14 \%$ in the USA.

This raises the question whether these findings really justify such a drastic step. There is, beyond doubt, a strong age-relatedness, but the increased risk for suicidal behaviour in young adults aged $<25$ years alone is only just statistically significant. The second main finding, of the age-relatedness of suicidal behaviour, is strongly dependent on the robust suicide protective effect in higher ages, which per se also does not necessarily suggest a suicide warning that has general effects on overall antidepressant prescription rates.

The discovery of age as an influential variable of antidepressant-induced suicidal behaviour significantly adds to our knowledge, opens new research fields and suggests closer suicidality monitoring in clinical daily routine. However, though the paper by Stone and colleagues is a landmark in suicide research, the consequential FDA black-box warnings may not have been fully justified.

Florian Seemüller, Hans-Jürgen Möller, Michael Obermeier, Rebecca Schennach-Wolff, Michael Riedel

Ludwig-Maximilians-University Munich, Munich, Germany

Competing interests: None.

1. Möller HJ. Is there evidence for negative effects of antidepressants on suicidality in depressive patients? A systematic review. Eur Arch Psychiatry Clin Neurosci 2006;256:476-96.

2. Gibbons RD, Brown $\mathrm{CH}$, Hur K, et al. Early evidence on the effects of regulators' suicidality warnings on SSRI prescriptions and suicide in children and adolescents. Am J Psychiatry 2007;164:1356-63. 


\section{EBMH Review: antidepressants associated with increased risk of suicidality in adults aged less than 25 years}

Evid Based Mental Health 2010 13: 52

doi: 10.1136/ebmh.13.2.52

Updated information and services can be found at:

http://ebmh.bmj.com/content/13/2/52.full.html

\section{These include:}

Data Supplement

References

Email alerting service
"Web Only Data"

http://ebmh.bmj.com/content/suppl/2010/05/31/13.2.52.DC1.html

This article cites 3 articles, 1 of which can be accessed free at: http://ebmh.bmj.com/content/13/2/52.full.html\#ref-list-1

Article cited in:

http://ebmh.bmj.com/content/13/2/52.full.html\#related-urls

Receive free email alerts when new articles cite this article. Sign up in the box at the top right corner of the online article.

Topic Articles on similar topics can be found in the following collections

Collections

\section{Suicide (psychiatry) (201 articles)}

Epidemiology (1440 articles)

Notes

To request permissions go to:

http://group.bmj.com/group/rights-licensing/permissions

To order reprints go to:

http://journals.bmj.com/cgi/reprintform

To subscribe to BMJ go to:

http://group.bmj.com/subscribe/ 